Www.jmscr.igmpublication.org

Index Copernicus Value: 79.54

ISSN (e)-2347-176x ISSN (p) 2455-0450

crossref DOI: https://dx.doi.org/10.18535/jmscr/v7i4.70

\title{
Role of Various Biochemical Markers for the Differential Diagnosis of Exudative and Transudative Pleural Effusion and its Comparison with Traditional Light's Criteria
}

\author{
Authors \\ Nita Sahi ${ }^{1}$, Navneet Kumar Dwivedi ${ }^{2}$ \\ ${ }^{1}$ Associate Professor Dept. of Biochemistry Pacific Medical College \& Hospital Udaipur (Rajasthan), India. \\ ${ }^{2}$ PG Student Dept. of Biochemistry Pacific Medical College \& Hospital Udaipur (Rajasthan), India \\ Email: shubhamjain094@gmail.com, Mob.9116051017
}

\begin{abstract}
Background: Pleural effusion is an excessive accumulation of fluid in the space lies between the lung and chest wall i.e. pleural space ${ }^{1}$. In normal condition, pleural space contains a film of fluid (near about of $10 \mathrm{ml}$ of fluid on each side) between the parietal and visceral pleural. This pleural fluid acts as a lubricant and allows the visceral pleural to slide along the parietal during respiratory movements.

Aim of study: Role of various biochemical marker for the differential diagnosis of Exduative and Transudative pleural effusion.

Study Area: The present study will be conducted in PMCH, Udaipur.

Result: When comparing Exudative and Transudative pleural effusion the concentration in Exduative patients ADA level in pleural fluid (80.30 \pm 35.03$)$, serum (36.97 \pm 14.50$)$, ALP level in pleural fluid (129.41 \pm 41.34$)$, serum $(190 \pm 87.65)$, LDH level in pleural fluid $(507.75 \pm 195.90)$, serum $(739.03 \pm 259.59)$, The observation shows statistically significant differences $(p)$ in both groups.

Conclusion: We observed that transudative pleural effusion appears in advance age groups but exudative pleural effusion seen in early age groups, the reasons behind that the etiological factor involve for transudative pleural effusion (Congestive cardiac failure, Chronic renal failure, Liver Cirrhosis) appear later in life i.e. $>50$ year.
\end{abstract}

Keywords: $A D A, A L P, L D H$, Pleural Effusion.

\section{Introduction}

Pleural effusion is an excessive accumulation of fluid in the space lies between the lung and chest wall i.e. pleural space ${ }^{1}$. In normal condition, pleural space contains a film of fluid (near about of $10 \mathrm{ml}$ of fluid on each side) between the parietal and visceral pleural. This pleural fluid acts as a lubricant and allows the visceral pleural to slide along the parietal during respiratory movements $^{2}$.
Pleural effusion caused by a misbalance between fluid production and fluid removal, it is often the first manifestation of a cardiac or pulmonary disease $^{3}$. Pleural effusion is a common chest problem, yet it is difficult to establish the etiological diagnosis in as many as $20 \%$ cases in spite of good history, through clinical, radiological, full examination of aspirated fluid and pleural biopsy ${ }^{4}$. So there is a need of simple, 
rapid and reliable diagnostic test $\mathrm{t}$ establish the etiology of pleural effusion.

Four types of fluids can accumulate in the pleural space:
1. Serous fluid (hydrothorax)
2. Blood (haemothorax)
3. Chyle (chylothorax)
4. Pus (pyothorax or empyema)

\section{Methodology}

Study Area: The present study will be conducted in $\mathrm{PMCH}$, Udaipur.

Study Design: The study will design and undertaken in the Central laboratory of $\mathrm{PMCH}$ Udaipur. The cases of this study compare the role of biochemical markers (ALP, ADA and LDH) for the differential diagnosis of exduative and transudative pleural effusion.

Study Period: March 2018 to Dec.2018

Sample Population: We have taken a total of 100 (male and female of all age) patients with pleural effusions of diverse etiologies, attending various departments (pulmonary, cardiology, surgery and gynecology) of Pacific Medical College and Hospital Udaipur Rajasathan. Patients with malignant pleural effusion from Pacific Medical College and Hospital in this study.

Sample Size: We divided 100 patients into group 1 and group 2. Group 1 include exduative 60 patients out of which 30 Patients of tubercular pleural effusion, 13 patients with para pneumonic pleural effusion or emphysema, 7 patients with malignant pleural effusion, and ten patients of exudates other than the above causes. Group 2 include transduative 40 patients out of which five were of nephritic syndrome, two patients of pulmonary embolism, eighteen patients of congestive cardiac failure, and 14 patients of chronic renal failure.

Inclusion Criteria: A total of 100 patients were taken out of which 60 were exduative and 40 were transduative.

Exclusion Criteria: All the patients not having pleural effusion are excluded from the study.
Statically Analysis: The collected data was analyzed using SPSS windows (version 20). Normality of data was checked using Shapiro Wilk's test. The parameters those were normally distributed were analyzed by parametric (independent samples $\mathrm{T}$ test) and the results were expressed in Mean \pm Standard deviation (SD). Parameters which showed non normal distribution were analyzed by non parametric (one way analysis of variance) and the results were expressed in Mean \pm Standard error (SE). All the results and observations are pressed as Tables, bar diagram (along with error bar). The cut off for significant was taken at $\mathrm{p}$ value equal to or less than 0.05 .

\section{Observation \& Result}

Table 1 Showing ADA, ALP and LDH (IU/L) in pleural fluid and serum in exudative effusion

\begin{tabular}{|l|c|c|c|c|}
\hline Parameter & $\begin{array}{c}\text { Pleural fluid } \\
\text { (Mean } \pm \text { SD) }\end{array}$ & $\begin{array}{c}\text { Serum } \\
\text { (Mean } \pm \\
\text { SD) }\end{array}$ & t value & $\begin{array}{c}\mathbf{p} \\
\text { value }\end{array}$ \\
\hline ADA & $\begin{array}{c}80.30 \pm \\
35.03\end{array}$ & $\begin{array}{c}36.97 \pm \\
14.50\end{array}$ & 8.851 & $0.001 *$ \\
\hline ALP & $\begin{array}{c}129.41 \pm \\
41.34\end{array}$ & $\begin{array}{c}190 \pm \\
87.65\end{array}$ & 4.842 & $0.001 *$ \\
\hline LDH & $\begin{array}{c}507.75 \\
\pm 195.90\end{array}$ & $\begin{array}{c}739.03 \\
\pm 259.59\end{array}$ & 5.509 & $0.001 *$ \\
\hline
\end{tabular}

In exudative condition, quantification of pleural fluid and serum ADA, ALP and LDH value were compared for the same (Mean \pm SD) The observation shows statistically significant differences ( $p)$ in both groups.

Figure 1 Comparison of pleural fluid with serum ADA and ALP (Mean \pm SD) in exudative condition

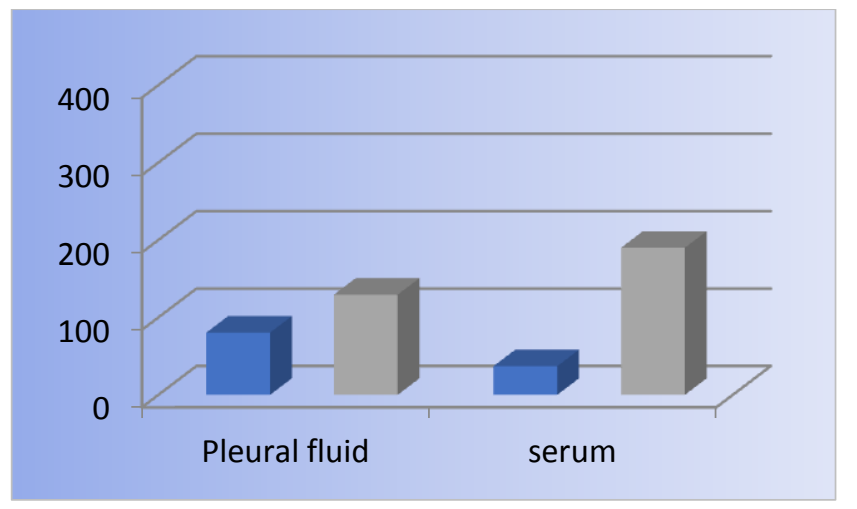


Table 2 Showing ADA, ALP and LDH (IU/L) in pleural fluid and serum in transudative effusion

\begin{tabular}{|l|c|c|c|c|}
\hline Parameter & $\begin{array}{c}\text { Pleural fluid } \\
\text { (Mean } \pm \text { SD) }\end{array}$ & $\begin{array}{c}\text { Serum } \\
(\text { Mean } \pm \text { SD) }\end{array}$ & t value & p value \\
\hline ADA & $20.32 \pm 2.68$ & $15.82 \pm 2.94$ & 7.14 & $0.001^{*}$ \\
\hline ALP & $56.12 \pm 8.29$ & $111.67 \pm 14.03$ & 21.54 & $0.001^{*}$ \\
\hline LDH & $134.65 \pm 35.01$ & $372.32 \pm 110.06$ & 13.05 & $0.001^{*}$ \\
\hline
\end{tabular}

In transudative condition, quantification of pleural fluid and serum ADA, ALP and LDH value were compared for the same (Mean $\pm \mathrm{SD}$ ) The observation shows statistically significant differences ( $p)$ in both groups.

Figure 2 Comparison of pleural fluid with serum ADA and ALP (Mean \pm SD) in Transudative Effusion

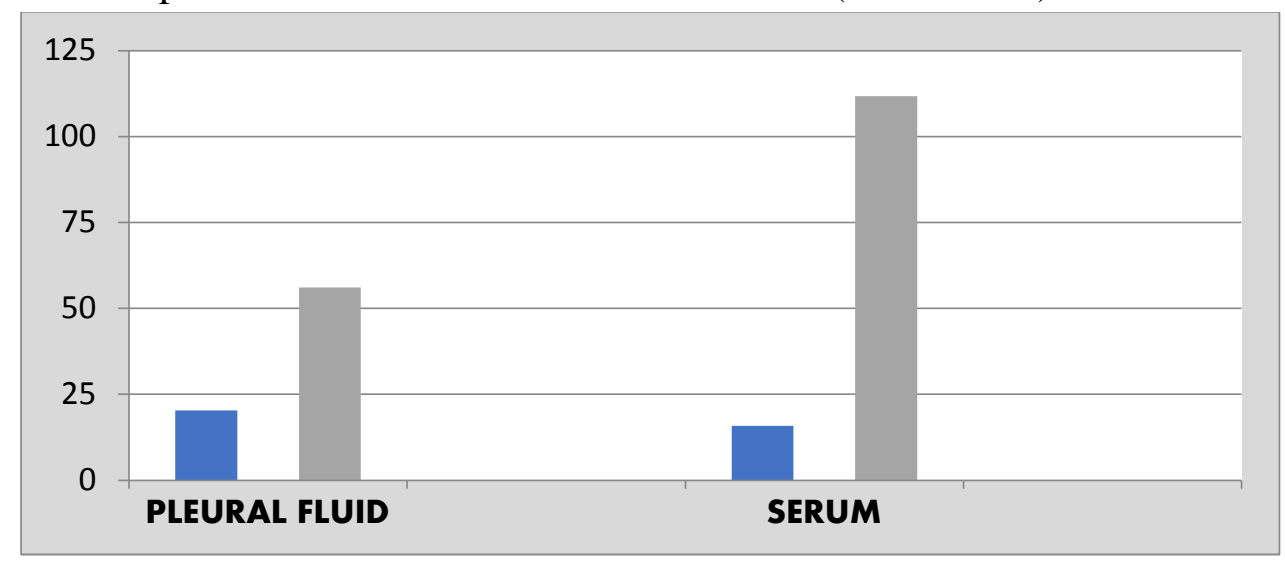

In present study, the mean serum adenosine deaminase level in exudates and Transudates are $36.96 \pm 14.50 \mathrm{IU} / \mathrm{L}$ and $15.82 \pm 2.94 \mathrm{IU} / \mathrm{L}$ respectively and they are statistically significant. The mean pleural adenosine deaminase level in exudates and transudates are $80.30 \pm 35.03 \mathrm{IU} / \mathrm{L}$ and $20.32 \pm 2.68 \mathrm{IU} / \mathrm{L}$ respectively and they are statistically significant.

In present study, the mean serum ALP level in exudates and transudates are 190 $\pm 87.65 \mathrm{IU} / \mathrm{L}$ and $111.67 \pm 14.03 \mathrm{IU} / \mathrm{L}$ respectively and they are statistically significant. The mean pleural fluid ALP level in exudates and transudates are 129.41土 $41.34 \mathrm{IU} / \mathrm{L}$ and $25.92 \pm 3.71 \mathrm{IU} / \mathrm{L}$ respectively and they are statistically significant.

In present study, the mean serum LDH level in exudates and transudtes are $739.03 \pm 259.59 \mathrm{IU} / \mathrm{L}$ and $372.32 \pm 11.03 \mathrm{IU} / \mathrm{L}$ respectively and they are statistically significant. The mean pleural fluid LDH level in exudates and transudates are $507.75 \pm 195.90 \quad$ IU/L $134.65 \pm 35.01 \quad$ IU/L respectively and they are statistically significant.

\section{Discussion}

Adenosine Deaminase level below 47 IU/L and these values correlate Maritz, Malan, de (1982) ${ }^{6}$, Inma Ocana et al $(1983)^{7}$, Jhamaria J.P. et al $(1988)^{8}$, Gupta D.K. Suri J.C. Goel A (1990) ${ }^{9}$, Gorguner, Cerei, Gorguner, $(2000)^{5}$ and other authors.

Alkaline phosphatase is an endogenous ectoenzyme, widely expressed in many organs that are exposed directly or indirectly to the external environment, like the gastrointestinal tract and the lungs. ALP ratio for differentiating exudates from transudates, and These values of ALP correlated with A.A. Jadav et al (2009) ${ }^{11}$, K.B. Gupta et al $(2004)^{10}$, M.A. Lone et al (2003) ${ }^{12}$, Gazquez et al $(1997)^{13}$,Kiroshka V.S. et al (1990) ${ }^{14}$.

In our study, the mean pleural fluid and serum Lactate Dehydrogenase level as well as pleural fluid and serum ratio are significantly raised in exudative pleural effusion than transudative effusion group and our study correlate with, Jadhav MV et al. (2007) ${ }^{15}$, Joseph J et al. (2002) ${ }^{16}$, Hence serum and pleural LDH level as well as 
pleural / serum LDH ratio may be helpful for differentiating exudates from transudates.

\section{Conclusion}

It is clinically important to classify pleural fluids into exudates and transudates because this is indicative of the underlying pathophysiological process involved. Such a distinction allows appropriate investigations to be instigated, enabling better patient management.

1) We observed that transudative pleural effusion appears in advance age groups but exudative pleural effusion seen in early age groups, the reasons behind that the etiological factor involve for transudative pleural effusion (Congestive cardiac failure, Chronic renal failure, Liver Cirrhosis) appear later in life i.e. $>50$ year (mean age $\pm \mathrm{SD}=55.17$ \pm 7.23 in our study) but exudative pleural effusion occurs mostly by infections causatives, so it occurs in all age groups (mean age $\pm \mathrm{SD}=45.4 \pm 13.05$ in our study), Table no 11. In our study we found that statistically significance in age variation in both the groups, but we not found the correlative data for the same.

2) ADA, ALP, LDH, protein and uric acid found statistically significance in pleural to serum in intra and inter groups and results compare and confirmed with light's criteria. We conclude that the other biochemical parameter have diagnostic significance when light's criteria alone not able to settle the diagnosis. But in some diseases where specific markers increase out of proportion.

\section{Bibliography}

1. Atalay F, Ernam D, Hassanoglu HC, Karalezli A, Kaplan O. Pleural adenosine deaminase in the separation of transudative and exudative pleural effusions. Clin Biochem 2005 Dec; 38(12): 1066-70.Epub 2005 Oct 13.

2. Agarwal Mukesh, Jitendra Nath, Mukerji PK, Shrivastava VML. A study of serum adenosine deaminase activity in sputum negative patients of pulmonary tuberculosis. Ind J Tubercul 1991; 38:139-41.

3. Basu A, Chakrabarti I, Ghosh N, Chakraborty S. A clinicopathological study of tuberculous pleural effusion in tertiary care hospital. Am Trop Med Public Health 2012; 5:168-72?

4. Chetty KG (1985) Trabsudative pleural effusions. Clin chest Med.6:49-54.

5. Gorguner MI Cerci M, Gorguner L. Determination of adenosine deaminase activity and its isoenzymes for diagnosis of pleural effusions. Respirology 2000 Dec; 5(4):321-24.

6. Burgess LJ, Martiz FJ, Taljaard JJ. Comparative analysis of the biochemical parameters used to distinguish between pleural transudates and exudates. Chest. 1995; 107:1604-9.

7. Inma Ocana, jose M. Martinez - Vazquez, Rosa M. Segura, et. 1983, “Adenosine deaminase in pleural effusions", Chest, 84(1):51-53.

8. Jhamaria JP, Jenaw RK, Luhada SKI Mathur DK, Parihar HL, Sharma SK. Serum adenosine deaminase in differential diagnosis of pulmonary tuberculosis and common nontubercular respiratory diseases. Indian J Tubercul 1988;35:25-27.

9. Gupta DK, Suri JC, Goel A.Efficacy of adenosine deaminase in the diagnosis of pleural effusions. Indian $\mathbf{J}$ Chest Dis Allied Sci.1990 Oct-Dec;32(4):205-8.

10. Gupta K B, Ghalaut V, Gupta PP, Arora $\mathrm{P}$, Tandon S. Efficacy of pleural fluid alkaline phosphatase and its ratio to serum levels in distinguishing exudates from transudates. Lung India 2004;21:46-9.

11. Jadhav AA, Bardapurkar JS, Jain A. Alkaline phosphatase: Distinguishing between Tuberculous and nontuberculous pleural effusion. Lung India 2009;26:7780. 
12. Mushtaq A. Lone, Abdul Wahid, S.M. Saleem, Parvaiz Koul, Gh. Nabi Dhobi and A. Shahnawa. Alkaline Phosphatase in Pleural Effusions. Indian J chest Dis Allied Sci 2003;45:161-163.

13. Gazquez I, Porcel JM, Vives M. Vicente de Vera MC, Rubio MI Rivas MC. Comparative analysis of Light's criteria and other biochemical parameters for distinguishing transudates from exudates. Chest 1997 Aug; 112(2): 569-570.

14. Kiroshka VS, Tsymbalar GG, Zhurzha LE, Tudos TP.A method of differentiating transudates and exudate. Probl Tu berk 1990;8:62-63.

15. Jadhav MV, Ketkat S, Patil T, Shingade MS. Pleural fluid analysis wih traditional and additional parameters. Indian $\mathrm{J}$ Pathol Microbiol 2007 Apr; 50(2):415-9.

16. Joseph J, Badrinath P, Basran GS, Sahn SA. "Is albumin gradient or fluid to serum albumin ratio better than the pleural fluid lactate dehydrogenase in the diagnostic separation of pleural effusion?" BMC Pulmonary Medicine 2002;2:1. 